\title{
Negative Pressure Wound Therapy with Multiple Drainage Holes for the Treatment of Pressure Ulcer with Undermining: Case Reports
}

\author{
Hiroyuki Miura, Yumiko Ito, Tomoko Matsuda, Ayano Abe, Syun Kitaba \\ Department of Dermatology, Kinki Central Hospital, Itami, Japan. \\ Email: tori2@mac.com
}

Received January $4^{\text {th }}, 2013$; revised February $7^{\text {th }}, 2013$; accepted February $15^{\text {th }}, 2013$

\begin{abstract}
Noninvasive treatment of pressure ulcers with undermining is often difficult. To decrease the risk of bleeding in such conditions, negative pressure wound therapy (NPWT) has been applied. We treated a pressure ulcer with wide undermining using NPWT after opening drainage holes in the undermined area. This method can reduce the risk of bleeding and promote the rapid closure of the undermined area.
\end{abstract}

Keywords: Negative Pressure Wound Therapy; Pressure Ulcer; Undermining

\section{Introduction}

Negative pressure wound therapy (NPWT) is gaining popularity as an acute and chronic wound management, and can prevent bacterial infection, eliminate edema, and facilitate neovascularization [1-3].

Noninvasive treatment of pressure ulcers with undermining is often difficult. To decrease the risk of bleeding in such conditions, NPWT has been applied. However, closure of the undermined area requires a long operative time $[3,4]$. Therefore, we treated a pressure ulcer with wide undermining using NPWT after opening drainage holes in the undermined area. This method can reduce the risk of bleeding associated with incising the entire undermined area and promote the rapid closure of the undermined area.

\section{Case Reports}

\subsection{Case 1}

An 86-year-old woman, with right-sided paralysis due to cerebral infarction, had been suffering from a Stage III pressure ulcer for 3 months. Examination revealed a pressure ulcer $(4 \times 3 \mathrm{~cm})$ with a widely undermined area $(8 \times 5 \mathrm{~cm})$ on the right great trochanter. Blood tests revealed a low albumin level $(3.2 \mathrm{~g} / \mathrm{dL})$ and slight anemia $(\mathrm{Hb}, 10.4 \mathrm{~g} / \mathrm{dL})$. NPWT using the polyurethane foambased NPWT system (RENASYS; Smith \& nephew, Florida, USA) at -80 to $-120 \mathrm{mmHg}$ for a month neither reduced the size of the ulcer nor improved the undermining (Figure 1(A)). Therefore, we opened several drainage holes using a 5-mm punch biopsy needle on the undermined surface under local anesthesia, instead of incising the entire undermined area (Figure 1(B)). After confirming the absence of bleeding over night, we started NPWT again at $-120 \mathrm{mmHg}$.

Twice a week, when the dressing had been changed, basic fibroblast growth factor (bFGF) (Fiblast splay; Kaken, Tokyo, Japan) was applied to the ulcer and drainage holes.

Two weeks after this treatment, the sizes of the ulcer and the undermining were $3 \times 2 \mathrm{~cm}$ and $3 \times 1.5 \mathrm{~cm}$, respectively (Figure 1(C)). During 2 weeks of additional NPWT, no improvement of undermining was observed. Therefore, we performed a histological examination of the undermined area. In the specimen of the undermined area, which closed rapidly, the tissue of the ceiling portion was granular. On the other hand, in the specimen of the remainder of the undermined area, the ceiling portion was covered with irregular epithelium, thought to have prevented closure of the dead space (Figure 1(D)). Therefore, we stopped NPWT and continued bFGF and hydrocolloid dressing and so on, sometimes performing debridement of the ceiling surface using a curet. After 2 weeks closure of the undermined area was observed, and there was complete epithelialization of the ulcer after 5 weeks (Figure 1(E)).

\subsection{Case 2}

An 80-year-old woman had been suffering from stage III sacral pressure ulcer for several years, consist of an ulcer 


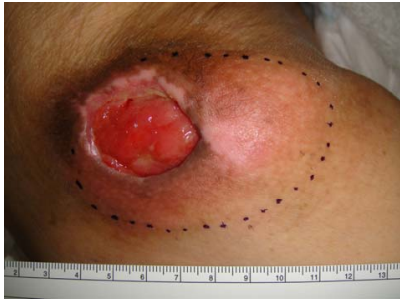

(A)

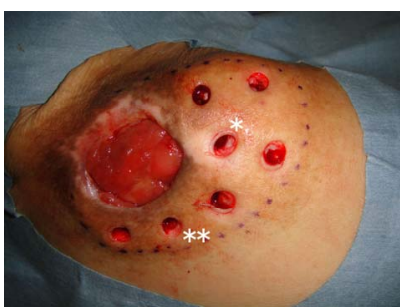

(B)

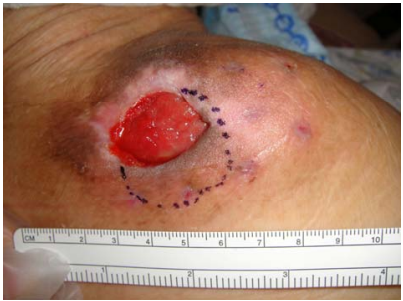

(C)

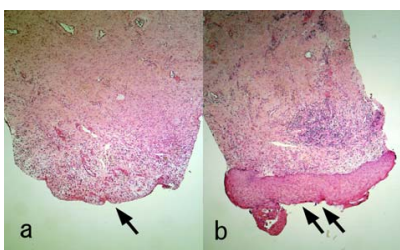

(D)

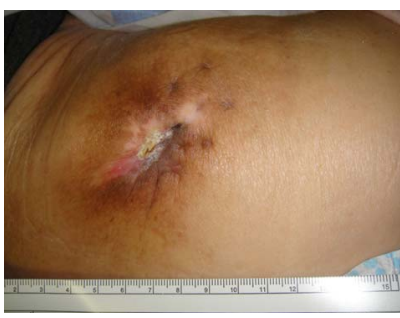

(E)

Figure 1. (A) Pressure ulcer $(4 \times 3 \mathrm{~cm})$ with wide undermined area (dotted line: $8 \times 5 \mathrm{~cm})$; (B) Drainage holes were made with a 5-mm punch biopsy needle in the undermined area before NPWT; (C) Two weeks after treatment, the size of the ulcer and the undermining were $3 \times 2 \mathrm{~cm}$ and $3 \times 1.5$ $\mathrm{cm}$, respectively. All of the drainage holes closed and left a slight scar. (D) Histological appearance of the ceiling of the undermined area (H\&E stain, $\times 40$ magnification). (a) $A$ specimen of undermining that closed rapidly $(1 \mathrm{~B}, *)$; The ceiling portion consisted of granular tissue (arrow); (b) The remainder of the undermined area $(1 \mathrm{~B}, * *)$. The ceiling portion was covered with irregular epithelium (double arrow). (E) Complete epithelialization of the ulcer was observed.
$(3 \times 3 \mathrm{~cm})$ with an undermined area $(3 \times 3 \mathrm{~cm})$ and an ulcer $(1 \times 0.5 \mathrm{~cm})$ with an undermined area $(1.5 \times 1 \mathrm{~cm})$. When we opened drainage holes on the undermining (Figure 2(A)), we investigated the ceased piece of undermining by dermoscopy and found the existence of irregular epithelium in the ceiling portion of the undermining, which histologically confirmed later. After we performed debridement using a curet, we started NPWT with drainage holes on the undermining, in the same method as Case 1. After two weeks of NPWT both of the undermining were closed (Figure 2(B)).

\section{Discussion}

Pressure ulcers can form anywhere on the body, although they most frequently develop in the sacral area $(30 \%$ $40 \%)$. The great trochanter is another location where pressure ulcers occur frequently $(10 \%-15 \%)$ [4]. They are caused by pressure, traction, friction, or their combination.

The treatment of a pressure ulcer with undermining is challenging. It is recommended that an incision be made above the undermined surface, although this is an invasive approach that carries the risk of bleeding. To prevent bleeding, NPWT has been applied to such conditions. However, undermining closure requires a long operative time and is sometimes unsuccessful $[3,4]$.

To promote the closure of the undermined area, we administered a basic fibroblast growth factor (bFGF)

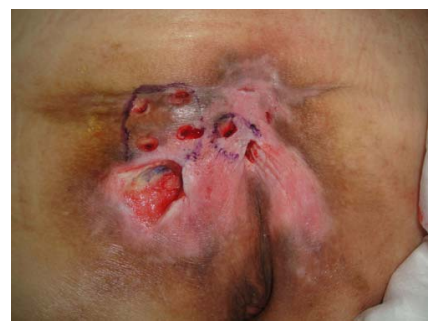

(A)

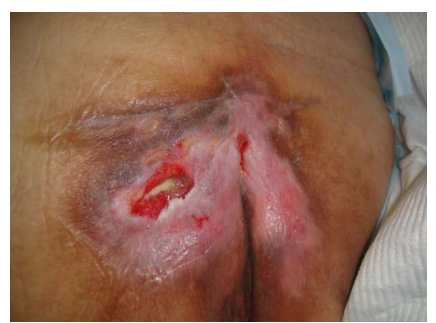

(B)

Figure 2. (A) Pressure ulcer $(3 \times 3 \mathrm{~cm})$ with an undermined area (line: $3 \times 3 \mathrm{~cm})$ on the left side of scrum and an ulcer $(1 \times$ $0.5 \mathrm{~cm}$ ) with an undermined area (line: $1.5 \times 1 \mathrm{~cm}$ ) on the right. The drainage holes, four on the left and one on the right side, were opened before NPWT; (B) Closure of undermining was observed after two weeks of NPWT. 
spray because bFGF has been reported to accelerate wound healing by promoting neovascularization, granulation, and epithelialization [5]. Furthermore, we hypothesized that the drainage holes created in the undermined area may decrease the dead space below the undermined area, thus allowing for strong contact between the ceiling of the undermined area and the bottom of the dead space during NPWT. In fact, the drainage holes gradually reduced in diameter following NPWT, and they were filled with high amounts of granulation tissue after NPWT and bFGF administration. After closure of the drainage holes, the granulation tissue likely extended downward to the bottom, as the resultant scars seemed to adhere tightly to the underlayer without mobility.

In both of our cases, irregular epithelialization was observed in the ceiling of the undermined area. This irregular epithelium is believed to prevent undermining closure; therefore, this tissue must be identified by histology, dermoscopy, or other methods before NPWT with drainage holes can be performed in the undermined area.

Thus, the granulation tissue in drainage holes may play a role as an anchor that fixes and encloses the undermining. In addition, we believe that NPWT with drainage holes created in the undermined area may become a therapeutic option for pressure ulcers with undermining.

\section{REFERENCES}

[1] A. Rahmanian-Schwarz, L. M. Willkomm, P. Gonser, B. Hirt and H. E. Schaller, "A Novel Option in Negative Pressure Wound Therapy (NPWT) for Chronic and Acute Wound Care," Burns, Vol. 38, No. 4, 2012, pp. 573-577. doi:10.1016/j.burns.2011.10.010

[2] M. Tachi, S. Hirabayashi, Y. Yonehara, G. Uchida, T. Tohyama and H. Ishii, "Topical Negative Pressure Using a Drainage Pouch without Form Dressing for the Treatment of Undermined Pressure Ulcers," Annals of Plastic Surgery, Vol. 53, No. 4, 2004, pp. 338-342. doi:10.1097/01.sap.0000129234.84192.d4

[3] M. J. Morykwas, L. C. Argenta and E. I. Shelton-Brown, "Vacuum-Assisted Closure: A New Method for Wound Control and Treatment: Animal Studies and Basic Foundation," Annals of Plastic Surgery, Vol. 38, No. 6, 1997, pp. 553-562. doi:10.1097/00000637-199706000-00001

[4] B. de Angelis, L. Lucarini, A. Agovino, A. Migner, F. Orlandi, M. Floris, V. Cervelli and C. Curcio, "Combined Use of Super-Oxidised Solution with Negative Pressure for the Treatment of Pressure Ulcers: Case Report," International Wound Journal, 2012. doi:10.1111/j.1742-481X.2012.00982.x

[5] H. Uchi, A. Igarashi, K. Urabe, T. Koga, J. Nakayama, R. Kawamori, K. Tamaki, H. Hirakata, T. Ohura and M. Furue, "Clinical Efficacy of Basic Fibroblast Growth Factor (bFGF) for Diabetic Ulcer," European Journal of Dermatology, Vol. 19, No. 5, 2009, pp. 461-468. 